Health and Social Security performance indicators, both activity and cost, when adjusted for case mix, are near the expected level; they compare favourably with other districts, particularly provincial teaching districts. Indeed, the Thames regions top the league table in "cost improvement" programmes.

Many other questions are raised by the report-not least the lack of information on priority services. But so what? Raising questions and the subsequent debate are part of health service planning. Should what might appear to be a parochial issue not be settled by the 12 districts and their regions unruffling their feathers and sitting down quietly to review their strategies and adjust them as necessary? The special funds made available to reduce the pressures inflicted by the Resource Allocation Working Party will lubricate the process and also reduce the pressures on ministers in what for them is an important year.

The problem should not be settled in this way, primarily because the issues raised in the report are not peculiar to the inner London districts: they just happen to have raised them. Patients are not behaving as planned: the Thames regions have relied on a $15 \%$ reduction in hospital admissions in inner London but so far there has been a $2.5 \%$ increase. The flow from outside London appears to be increasing, not decreasing. Bed reductions do not reduce activity-not if the number of consultants is not also reduced, and there are no realistic plans to do so. If, as is the case, the easy and most cost effective reductions have taken place by closing entire hospitals, what further reductions will have to take place to find the remaining $60 \%$ of the $£ 109 \mathrm{~m}$ ?

This is the nub of the issue and the not so hidden agenda behind the report. Can the Thames regions develop priority services, cope with demographic change, fund new developments in health care, and still run a viable acute service? Perhaps they cannot. Perhaps no part of the country can, and the concept that Britain can run a health service with a lower number of acute beds per head of population, with less of our gross national product going on health than most other countries, is akin to that adopted by Canute's courtiers. Waiting to see whether the tide will engulf us is not advisable. The DHSS and the regions must therefore tackle the issues raised in the report and in addition they must be seen to be tackling them. They should recognise that such debate will and should take place in public and welcome reports like this one.

They could in addition be looking across the Atlantic. If further savings can be achieved without compromising patient care then they will probably come from clinical work. In most hospitals the non-clinical budgets are virtually squeezed dry. The American hospital system has rapidly had to learn how to control and rationalise clinical activity because of the system of a fixed cost for each case. Some of that knowledge might be transferable to this country. We must also have some way of monitoring what is happening in the acute sector. The various agencies who pay the bills in American hospitals have advanced external audit systems that masquerade under the friendly title of peer review organisations. They look at both the process and the outcome of clinical activity. Perhaps what we need is a health advisory service for the acute hospital sector.

And, lastly, where we began-London. It should not distort the national picture but neither should its present and potential contribution to teaching and treatment be underused or run down piecemeal. Why not call its bluff? The only reason for other people from outside London to receive their care in London is that it is either cheaper than elsewhere because of its historic volume or better because of its special skills. An inner London health authority funded to provide local services and relying on an internal NHS market to attract the rest of its money might tackle the issues raised in Back to Back Planning rather faster than conventional planning systems.

District General Manager,

City and Hackney Health Authority,

St Bartholomew's Hospital,

London EC1A 7BE

1 Rivett G. The development of the London hospital system 1823-1982. London: King's Fund, 1986 King Edward's Hospital Fund for London. Planned health services for inner London. Back to back planning. London: King's Fund, 1987.

\section{Why the excess mortality from psychiatric illness?}

The association between psychiatric illness and premature mortality has long been known but surprisingly little studied. Esquirol had noted high mortality between 1784 and 1794 at Bicêtre, ${ }^{1}$ and Farr, in making the first psychiatric study in 1841 , considered that the risk of death was increased six to seven times for lunatics in British asylums. ${ }^{2}$ The major causes of death in earlier accounts of hospitals were gastrointestinal infections such as cholera, which killed 226 out of 601 residents in the West Yorkshire Lunatic Asylum in the autumn of $1849,{ }^{3}$ and respiratory diseases, especially tuberculosis, because of poor hygiene and overcrowding in large institutions in the United States, ${ }^{4}$ Norway, ${ }^{5}$ and Britain. ${ }^{6}$ Savino and Brody pointed out that the mortality in institutions was closely linked to the average length of stay and that this reflected the optimism of that period about recovery from mental illness ${ }^{7}$; mortality rates, in part, thus comment on the nature of psychiatric care.

Mortality is still greater for psychiatric patients than expected, although less excessive since the introduction of modern treatments and shorter durations of inpatient care. ${ }^{8}$ This increase occurs from suicide, accidental death, and natural causes among those previously psychiatrically ill and for all major psychiatric diagnostic groupings-organic states, schizophrenia, affective disorders, and neuroses and related conditions. ${ }^{9}$ It occurs in both sexes, in many different 9 countries and ethnic groups, and is independent of type N of treatment (Corten P, Ribourdouille M, unpublished observations $)^{10}$; this increased death rate is of real importance for public health.

The association between psychiatric illness and suicide is obvious and well known. ${ }^{10} 11 \mathrm{~A}$ depressive illness or another psychiatric disorder could be diagnosed retrospectively in most cases of completed suicide ${ }^{12}$; psychiatric morbidity was high among those for whom a coroners' open verdict was returned $^{13}$; and psychiatric illnesses are the most common predisposing causes for suicide. ${ }^{14}$ Similarly psychiatric illness is associated with accidental death. ${ }^{15-17}$ Those with psychiatric illnesses are more likely to be the victims of violence and are more likely to put themselves at risk; and alcohol and drug abuse is associated with other mental disorders and with risk of accidental death. ${ }^{18} 19$

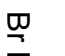


The more surprising finding is that the excess mortality remains even when suicide and accidental deaths are excluded. The highest increase is among those with organic psychotic conditions, especially any type of dementia, but is raised for all psychiatric diagnoses ${ }^{520}$ and paradoxically is greater for those aged under $40 .{ }^{11}$ Among the psychiatrically ill there have been accounts of sudden death, death with no organic disease, and also of unexpected death from known physical illness. ${ }^{21}$ Most of the excess mortality from natural causes is, however, from common conditions: cardiovascular disease and arteriosclerosis, ${ }^{22}$ pulmonary infection, ${ }^{23}$ and influenza. ${ }^{11}$ Whether there is an excess of deaths from malignancy is debatable. ${ }^{1122}$

Postulated causes for the excess mortality may be divided broadly into biological and psychosocial. Kendler has considered that genetic factors are important in mortality from trauma (suicide and accident) and those with schizophrenia and from diseases (natural causes) among those with neurotic conditions. ${ }^{24}$ Psychiatric illness and physical conditions resulting in death may be linked in three ways: the mentally ill may have an increased exposure to known causes of disease or death-for example, tobacco, alcohol, and dangerous driving; for a given degree of environmental exposure they may have an increased susceptibility to develop illness (psychosomatic disorder); and mental illness may adversely affect the outcome of a physical disease. ${ }^{25}$

The excess mortality could be accounted for by several different psychological theories. The cluster theory suggests that illnesses tend to cluster in different bodily and psychological systems in the same individual, that there is a higher concentration of some illnesses in a minority of the population, and that several illnesses tend to occur within a few years of the whole life span. ${ }^{26}$ The affect of hopelessness may be associated with the early stages of a severe physical illness, ${ }^{27}$ and many studies have looked at the association between adverse life events and the subsequent onset of serious illness and death. ${ }^{28}$ The experience of loss has been related to increased mortality, ${ }^{29}$ and the inability to communicate distressing emotion verbally (alexithymia) may be related to the onset of physical illness. ${ }^{30}$ Type $A$ behaviour patterns, with competitive striving, aggressiveness, hostility, and continuous working to time limits, have been related to an increased incidence of coronary heart disease. ${ }^{31}$ Very different life stresses may result in a common pathological pattern of illness resulting in death, ${ }^{32}$ and in certain predicaments the untoward event has had a last straw effect, resulting in premature death. ${ }^{33}$ Associations have atso been sought between abnormal psychological states and accident proneness. ${ }^{34}$

With this bewildering array of findings and theories one might concur with Tsuang and Simpson's answer to their self imposed question: "Mortality studies in psychiatry-should they stop or proceed?": "There is a continuing need for mortality studies and increased opportunities for integrating these investigations with other longitudinal studies of psychiatric population." 35 The study of mortality is the hardest fact of psychiatric epidemiology and can give useful information on the course of mental disorders and the efficacy of treatment.

Professor of Psychiatry,

St James's University Hospital,

Leeds LS9 7TF

1 Esquirol E. Des maladies mentales. Paris: Bailliere, 1838.

2 Farr W. Report upon the mortality of lunatics. Foumal of the Statistical Society 1841;4:17-33.
3 Wright TG. Reports on the origin and prognosis of pestilential cholera. London: Longmans, Brown, Green, and Longmans, 1850.

4 Malzberg B. Mortality among patients with mental disease. New York: New York State Hospital Press, 1934.

$5 \emptyset$ degard Ø. Mortality in Norwegian psychiatric hospitals. Acta Genetical (Basel) 1967;17:137-53. 6 Shepherd M. A study of the major psychoses in an English county. London: Maudesley Hospital, 1957. (Maudesley Monograph No. 3.)

Savino MT, Brody SA. Discharge and death rates in California state hospitals? 1852-1954. Arch Gen Psychiatry 1966;15:475-84.

8 Craig TJ. Mortality among psychiatric in-patients. Age adjusted comparison of populations before and after psychotropic drug era. Arch Gen Psychiatry 1981;38:935-8.

9 Sims ACP. Mortality in psychiatric patients. In: Koranyi EK, ed. Physical illness in the psychiatric patient. Springfield, Illinois: Charles.C Thomas, 1982:24-41.

10 Martin RL, Cloninger CR, Guze SB, Clayton PJ. Mortality in a follow-up of 500 psychiatric outMartin RL, Cloninger CR, Guze SB, Clayton PJ.
patients. Arch Gen Psychiatry 1985;42:47-70.

11 Black DW, Warrack G, Winokur G. The Iowa record-linkage study: 1 suicides and accidental deaths among psychiatric patients; 2 excess mortality among patients with organic mental disorders; 3 excess mortality among patients with 'functional' disorders. Arch Gen Psychiatry 1985;42:71-88.

12 Barraclough BM, Bunch J, Nelson B, Sainsbury P. A hundred cases of suicide: clinical aspects. Brf Psychiatry 1974;125:355-73.

13 Holding TA; Barraclough BM. Psychiatric mortality in a sample of London coroner's open verdicts. Br Psychiatry 1975;127:133-43.

14 Miles CP. Conditions predisposing to suicide: a suicide: a review. Nerv Men Dis 1977;164:231-46. 5 Holding TA, Barraclough BM. Psychiatric mortality in a sample of accidents. Br $\mathcal{F}$ Psychiatry 1977;130:244-52.

16 Rorsman B, Hagnell O, Lanke J. Mortality in the Lundby study (Natural death in different forms of mental disorder in a total population investigated during 25-year period). Neuropsychobiology 1982;10:83-9.

17 Sims ACP. Head injury, neurosis and accident proneness. In: Trimble MR, ed. Advances in psychosomatic medicine 13: Interface between neurology and psychiatry. Basel: Karger, 1985:49-70. Kaye S. Influence of alcohol on traffic deaths in Puerto Rico 1972. Bol Assoc Med PR 1973;65: 135-9.

19 Mason P. Mortality among young narcotic addicts. Journal of Mount Sinai Hospital, New York 1967;34:4-10.

20 Ciompi L. Catamnestic long-term study on the course of life and ageing of schizophrenics. Schizoph Bull 1980;6:606-18.

21 Ellman JP. Sudden death. Can f Psychiatry 1982;27:331-3.

22 Sims ACP, Prior MP. Arteriosclerosis-related deaths in severe neurosis. Compr Psychiatry 1980;23:181-5.

23 Saugstad LF, Ødegard Ø. Mortality in psychiatric hospitals in Norway. Acta Psychiatr Scand 1979;59:431-47.

24 Kendler KL. A twin study of mortality in schizophrenia and neurosis. Arch Gen Psychiatry 1986;43:643-9.

25 Sims ACP. Hypotheses linking neuroses with premature mortality. Psychol Med 1978;8:255-63. 6 Hinkle LE, Wolff HG. 'The nature of man's adaptation to his total environment and the relation of this to illness'. Arch Intern Med 1957;99:422-60.

27 Schmale AH, iker HP. The affect of hopelessness and the development of uterine cervical cancer in women with atypical cytology. Psychosom Med 1966;28:714-21.

28 Rahe R, Romo M, Bennett L, Siltanen P. Recent life changes, myocardial infarction and abrupt coronary death. Arch Intem Med 1974;133:221.

29 Parkes CM, Benjamin B, Fitzgerald RG. Broken heart: a statistical study of increased mortality among widows. BrMed $\mathcal{F} 1969 ;$;i: $740-3$.

30 Nemiah JC, Sifneos PE. Affect and fantasy in patients with psychosomatic disorders. In: Hill OW, ed. Modern trends in psychosomatic medicine. London: Butterworths, 1970:26-34.

31 Friedman M, Rosenman RH. Type A behaviour pattern: Its association with coronary heart disease. Ann Clin Res 1971;3:30.

32 Selye H. The stress of life. New York: McGraw-HiH, 1956.

33 Bennet G. Bristol floods 1968 . Controlled survey of effects of health of local community disaster. BrMed F 1970;iii:454-8.

34 Connolly J. Accident proneness. Hosp Med 1981;6:470-81.

35 Tsuang MT, Simpson JC. Mortality studies in psychiatry: should they stop or proceed? Arch Gen Psychiatry 1985;42:98-103.

\section{Asymptomatic hyperuricaemia}

Defining hyperuricaemia exactly is difficult, ${ }^{1}$ but practically it is a urate concentration above $420 \mu \mathrm{mol} / \mathrm{l}$ in men and $360 \mu \mathrm{mol} / 1$ in women. Sometimes hyperuricaemia will be found on routine screening in a person who has never had gout, and as it may be a risk factor for gout, renal disease, and ischaemic heart disease the question arises whether any treatment should be offered.

Prolonged hyperuricaemia certainly carries a risk of gouty arthritis proportionate to its severity and duration. The prevalence of gout is high in populations whose uric acid concentrations are above those found in Europe, and the height of the serum urate concentration correlates with the prevalence of gout. Data from the Framingham study showed that $90 \%$ of those with urate concentrations above $540 \mu \mathrm{mol} / \mathrm{l}$ had gout, ${ }^{2}$ but only $10 \mathrm{men}$ had this degree of hyperuricaemia and other studies have not confirmed such a high incidence of gout. For example, Fessel found that only three of 66 men with concentrations above $540 \mu \mathrm{mol} / 1$, in 